\title{
¿Hasta cuándo la religión? ${ }^{1}$ For how long will Religion last? MERCÈ Rius
}

\author{
Universidad Autónoma de Barcelona
}

RESUMEN. Un problema sociopolítico candente es el grado de representatividad pública que merezcan las religiones. Esta nota despliega el «estado de la cuestión» vertebrándolo en actitud crítica hacia el argumento básico común a los distintos interlocutores: la libertad de conciencia entendida como libertad de elección. No cabe identificarlas sin cancelar así la exigida separación entre lo religioso y lo político. Ahora bien, tal cancelación no solo se esté dando en la práctica, sino en los esquemas teóricos de quienes apoyan la laicidad desde dicha libertad para elegir. Como todo ello concierne al «monoteísmo de la razón», el discurso filosófico al respecto no debería quedarse en simple mediador entre las partes.

Palabras clave: Ateísmo práctico, conversión, inmanencia, libertad de contrato, libertad de credo, libertad de culto, mística, monoteísmo, sociedad laica, sociedad secularizada, teología, tradición, trascendencia.
Abstract. A hot sociopolitical issue today is the extent to which religions should be publicly represented. This text discusses the «state of the question» critically focusing on the main and common argument used by all the experts: liberty of conscience understood as freedom of choice. We are not allowed to identify both kinds of freedom without erasing the necessary division between religion and politics. Nevertheless, the elimination of this division not only occurs in practice but also in the theoretical outlines of the advocates of secularism based on freedom of choice. As the whole question concerns the «monotheism of reason», the philosophical discourse should not be a simple mediator between the different parts.

Key words: Practical atheism, conversion, immanence, freedom of contract, freedom of belief, freedom of cult, mysthicism, monotheism, secular society, secularized society, theology, tradition, transcendence.

Buena es la sal; pero si la sal se vuelve insípida, ¿con qué se sazonará? Lc 14:34

La religión se ha convertido de nuevo en un problema político. No me refiero con ello a la política internacional; esto es, ni a lo que ha dado en llamarse el choque de civilizaciones ni a las señas identitarias de carácter

${ }^{1}$ Este trabajo se inscribe en el proyecto de investigación "La religión en el espacio público democrático. Formas de laicidad» (FFI 2009-07433 del Ministerio de Ciencia e Innovación). 
religioso que algunas naciones de todo el mundo ostentan en su lucha por conseguir la independencia. Mi único posicionamiento acerca de esos dos extremos se reduce a calificarlos de «inter-nacionales», con lo que me opongo a su categorización respectiva en términos de «civilización» y de «constitucionalismo». ${ }^{2}$ Por lo demás, está claro que no debiera hablarse en ninguno de ambos casos de «retorno del fenómeno religioso», pues siempre estuvo ahí, aunque nuestros más celebrados pensadores hayan hecho en su gran mayoría, hasta la fecha, oídos sordos. Lo que sí se antoja como una especie de regreso es la cohabitación en un mismo Estado de confesiones religiosas tan eventualmente incompatibles cuanto semejantes entre sí. No se trata ahora, claro está, de las diferentes sectas del cristianismo que azotaron Europa con las «guerras de religión»; ${ }^{3}$ pero sí, especialmente, de los tres grandes monoteísmos. Tampoco resulta, no obstante, del todo cierto que tal situación fuera antes desconocida en el Estado moderno. Puesto que la reflexión sobre el tema se anuncia ardua, cito solo para espolearla, a modo de introito, un juicio histórico de Bertrand Russell en Por qué no soy cristiano:

La persecución de las formas impopulares de inteligencia es un peligro muy grave para cualquier país y con frecuencia ha sido la causa de la ruina nacional. El ejemplo típico es España, donde la expulsión de los judíos y de los moriscos dio lugar a la decadencia agrícola y a la adopción de un sistema financiero completamente absurdo. Estas dos causas, aunque sus efectos quedaron encubiertos al principio por el poder de Carlos V, fueron las principales responsables de la decadencia de España desde su posición dominante en Europa. ${ }^{4}$

Sin duda, también hoy están en juego razones económicas, que a nuestras alturas apenas se distinguen de las políticas. Cuando menos queda descartado por irrisorio que la política de un Estado confíe más en el poder de la Iglesia (como al parecer hizo el monarca español) que en el de las instancias económicas supraestatales (por difusas que también nos resulten, aunque en un sentido muy distinto al de aquel entonces). Pero no es mi intención aquí y ahora abordar ese aspecto, sino centrarme en la pregunta por los límites entre política y religión desde una perspectiva filosófica.

Como es sabido, los límites entre religión y política se expresan actualmente mediante dos conceptos: laicidad y secularización. A menudo se usan

${ }^{2}$ Quienes se oponen a las aspiraciones soberanistas contra el Estado de hecho argumentan, cómo no, en nombre del Estado de derecho; a ello me refiero con el término «constitucionalismo».

${ }^{3}$ Las denomino «sectas» porque esto eran al principio. Así llamo de paso la atención sobre lo relativo del concepto.

${ }^{4}$ A continuación pronostica «efectos semejantes» en Alemania y Rusia. Escribía esto en un artículo de 1940, «La libertad y las universidades», que luego se incluyó en una edición conjunta bajo el título de la famosa conferencia. B. Russell, Por qué no soy cristiano, Barcelona, Edhasa, 2009, p. 244. También Joan Fuster constata (en Nosaltres, els valencians) la ruina política y económica que precipitó en los territorios catalanoaragoneses dicha expulsión. 
como sinónimos; con matices distintos, por tanto, en función de los respectivos contextos. En Europa se llama laicidad, y en Estados Unidos secularización, a la neutralidad del Estado respecto a las diversas creencias religiosas practicadas en él. Suele insistirse en que neutralidad equivale a aconfesionalidad, pero no a ateísmo ni represión alguna de tales creencias. Ahora bien, por razones históricas, al nacer el laicismo en Francia con la república posrevolucionaria, digamos que es mucho menos proclive a la religiosidad que el secularismo de Estados Unidos, cuya independencia se forjó, por el contrario, en el seno de un acendrado espíritu religioso. En fin, todo esto se ha repetido ya un montón de veces en numerosos artículos y estudios, tantas como se ha advertido que los europeos barajamos ambos términos, mientras que en Estados Unidos, país poco dado al historicismo y mucho al ensimismamiento, ignoran completamente el uso del primero.

Por lo general, en Europa se atribuye la laicidad al Estado y la secularización a la sociedad. Llamamos sociedad secularizada a aquella cuya racionalidad dominante $-\mathrm{u}$ orden racional ${ }^{5}$ se compone de elementos que fueron en el pasado dogmas religiosos, ahora ya «traducidos» a representaciones conceptuales o, si se prefiere, a enunciados que conllevan un sentido mundano - no trascendente. Puesto que la tradición anglosajona se guarda de conceder al Estado una entidad autónoma capaz de sobreponerse a la sociedad civil, ${ }^{6}$ parece lógico que en Estados Unidos se aplique también al primero la denominación propia de la segunda. Por el contrario en Europa la extrapolación semántica consiste en calificar de «laica» a la misma sociedad. ${ }^{7}$ Vamos aquí a dejar de lado si se trata de la forma lingüística que adopta la vocación liberal en un medio históricamente dominado por el estatalismo. Lo que nos interesa es su relación con el fenómeno religioso.

Quizá la tendencia a usar «laica» en vez de «secularizada» para referirse a la sociedad obedezca a un deseo de acallar las voces que propician la «desecularización». En efecto, ésta solo resultaría factible si lo secularizado - como afirman algunos - conserva dentro de sí a lo religioso en tanto que, dándole una nueva forma en nuevas circunstancias, hace de transmisor de sus contenidos, los perpetúa. Abundaba en ello Carl Schmitt, que glosó libremente: ¿para qué preocuparse de las variaciones formales de poca monta, si se inscriben todas ellas en la forma omniabarcante que es la propia religión? ${ }^{8}$ Piénsese en la estructura teológica del último despliegue triunfan-

${ }^{5}$ La expresión es redundante, al menos según la tradición de los clásicos.

${ }^{6}$ Hobbes sería la excepción que confirma la regla al invertir el signo de la indistinción entre Estado y sociedad civil, en perjuicio de ésta.

7 A decir verdad, en el contexto norteamericano no se da extrapolación alguna, puesto que no se usa allí más que un término. Solo desde la perspectiva europea se observa la doble vertiente.

${ }^{8}$ Para una visión crítica de ello, cf. Hans Kelsen, «Dio e Stato» en Dio e Stato. La giurisprudenza come scienza dello spirito, Napoli, Roma, Edizioni Scientifiche Italiane, 1988, pp. 139-164. 
te de la razón occidental, es decir, de la historia humana según Hegel. O más modestamente, repárese en que el Estado moderno se apoyó durante mucho tiempo en una razón política tan absoluta como solo puede serlo la divinidad. ${ }^{9}$ En suma, a tenor de lo dicho, se abriría ante la posible desecularización un camino allanado. Pero no. Una sociedad laica constituye para unos algo más y para otros algo menos que una sociedad secularizada, porque se encontraría ya en un punto de no retorno. En una sociedad laica, «la sal se vuelve insípida», como sentencia el versículo bíblico. Y, como escribieran Nietzsche, Sartre o Kofman, el propio gusto rechaza cualquier justificación; no podemos explicarlo porque él es el que nos explica. Luego sus sanciones - que no sus «elecciones»- resultan decisivas.

Por ejemplo, en Europa, salvo las excepciones de rigor, el pleito norteamericano entre «evolucionistas» y «creacionistas» nos suena a música celestial. ${ }^{10}$ Para empezar, tenemos entendido que un Estado laico otorga crédito a la ciencia por encima de las religiones, como mínimo en materia de legislación que afecte a la supervivencia de las personas. Aunque admita la objeción de conciencia en el ámbito sanitario, no es de recibo la exención en lo que atañe a medio ambiente. ${ }^{11}$ Debe reconocerse, no obstante, que el evolucionismo posee un grado de verificabilidad muy inferior al de otras teorías científicas. Pero, justo por esa razón, no muestra una incompatibilidad insuperable con el dogma teológico del creacionismo. Solo unas facultades exegéticas muy mermadas pueden negarse a conciliarlos. Además, las creencias religiosas no hacen del individuo que las profesa un completo ignorante en temas científicos. En este aspecto, la desventaja podría recaer en el ciudadano no creyente - contra las tesis de Habermas-, por estar enclaustrado en un solo lenguaje a diferencia del creyente, hábil en ambos. Claro que tampoco presupondremos en el laico una total ausencia de imaginación, como si estuviera incapacitado para pensar la realidad a través de narraciones que prescinden de la existencia real de sus objetos. Es esa irrealidad de lo imaginario la que, en cambio, debería prohibir al presidente de Estados Unidos el finalizar sus discursos con un «iDios bendiga a América!» ${ }^{12}$

A mi entender, una sociedad secularizada se caracteriza por el intercambio discursivo entre ciudadanos creyentes y no creyentes (en sentido religioso, que no es el único). La persistencia en ella de las religiones no debería verse como un lastre que la racionalidad institucional fracasa en sacudirse,

${ }^{9}$ Algo de atributo divino tenía aún el «providencialismo» del Estado de bienestar.

${ }^{10}$ Entre las excepciones están quienes disertan sobre ello en clave publicista, con el aplomo de su laica indiferencia, al fin y al cabo; si no en un religioso mimetismo de todo lo que se cuece en Norteamérica.

${ }_{11}$ Desgraciadamente, las exenciones en este campo no obedecen a razones de conciencia, sino económicas; disimuladas por tanto, jamás opuestas frontalmente a los dictados científicos.

${ }^{12} \mathrm{Y}$ ello es así, debería ser así, al margen de que el presidente tenga fe religiosa e incluso de que Dios exista, dado que su existencia no puede ni verificarse ni falsarse racionalmente. 
ni tampoco como esperable reviviscencia de una semilla originaria, sino como dicha posibilidad de comunicación entre sus miembros sin necesidad de «autotraducirse». ${ }^{13} \mathrm{Al}$ fin y al cabo, el intento de comprensión mutua ya es en sí una modesta forma de «ponerse en el lugar del otro»; pero todo lo contrario de invadir la intimidad ajena robándole ofensivamente su propia forma de expresión. No hay, pues, comparación que valga con el lenguaje del jurista o el letrado, cuya índole impersonal nada quita ni pone a la intimidad de lo religioso.

Hoy todo el mundo sabe (o debería) ${ }^{14}$ que los endemoniados de los Evangelios eran epilépticos. En las sociedades precristianas se les tenía por aquejados de «la enfermedad sagrada». No por esto se nos ocurre ya santificarlos, pese a que ciertos éxtasis de los grandes místicos del pasado, el lejano y el reciente, iban probablemente asociados a esa enfermedad. Tampoco prevemos que, por literalidad evangélica, un ciudadano de nuestras sociedades democráticas se abstenga en tales circunstancias de acudir al neurólogo. Como mucho, tendrá que esforzarse el doble que el no creyente en la misma tesitura, pues quizá practique algún ritual suplementario, amén del de ingerir el fármaco. Por lo demás, me ahorraré comentarios sobre los esotéricos rituales a que puede sucumbir incluso un ateo cuando no queda esperanza médica, así como sobre el valor experimental del efecto placebo: no vienen a cuento. En una sociedad secularizada, por mucho que se desecularice, no es de temer que la epilepsia se convierta de nuevo en posesión diabólica. Y sin embargo, hoy no nos vendría nada mal un término procedente de la alquimia para poder referirnos a la cortisona como a la «panacea universal»». ${ }^{15}$ Así no confundiríamos las verdades racionales con la idolatría por la ciencia. Auténticamente libres, pues, para practicar o no la idolatría a sabiendas, en vez de levantar el espantajo del cientificismo contra la «superstición religiosa».

De todos modos, aunque el conocimiento científico haya impulsado la secularización, ésta no se predica del mismo en cuanto tal. Solo impropiamente se definiría a los corticoides como secularización de la panacea alquímica. A la razón se la llama «secularizada» en la estricta medida en que

${ }^{13}$ Charles Taylor sostiene una convicción parecida: «Pero ¿qué razón hay para pensar que la "razón natural" ofrece una especie de esperanto ideológico? ¿Fueron los conciudadanos seculares de Martin Luther King incapaces de entender lo que él defendía cuando abogaba por la igualdad en términos bíblicos?» Ch. Taylor, «Por qué necesitamos una redefinición radical del secularismo», en J. Habermas, Ch. Taylor, J. Butler, C. West, El poder de la religión en la esfera pública, Madrid, Trotta, 2011, p. 55.

${ }^{14} \mathrm{La}$ ignorancia generalizada en una cosa así no es laicismo, sino pésima formación cultural por nula transmisión del saber adquirido. Lo afirmado en el párrafo superior exige, pues, un aprendizaje y conocimiento mutuo de las ideas o «narraciones» defendidas por creyentes y no creyentes.

${ }^{15}$ La alquimia no es religión, obviamente; sino el antepasado mágico de la química. Creo que no hace falta precisar las diferencias entre lo mágico y lo religioso para seguir adelante. 
preside las relaciones entre seres humanos, o sea, las sociopolíticas. ${ }^{16}$ De ahí que una noción esencial en la historia de la filosofía, y por tanto en la evolución de la racionalidad occidental, haya sido la libertad de conciencia, de origen cristiano. Vamos a ella, aun si añade en principio complejidad a una reflexión difícilmente acotable.

Con frecuencia hemos oído a Xavier Rubert de Ventós acerca de la política que, cuando un grupo está en la oposición, aun el más conservador o hasta dogmático, con tal de ganar posiciones frente al adversario deja de argumentar en nombre de la verdad y apela a la libertad, que seguramente denostaba mientras se hallaba en el poder. Y es que la verdad solo se permite detentarla el que manda; sobre eso nos aleccionaron suficientemente primero Nietzsche y después Foucault. Pues bien, quienes juzguen a todas las religiones como atentados contra la libertad, o se muestren sensibles a los abusos que la Iglesia cometió a lo largo de su historia contra aquélla, sin duda interpretarán la actual actitud de jerarcas eclesiásticos e intelectuales más o menos orgánicos como manifestación del recurso descrito, e incluso como burda defensa de la libertad de mercado aplicada a la captación de prosélitos. En cualquier caso, no se exagera al notar que las religiones con firmes asideros institucionales pretenden hoy garantizarse un espacio «libre» para seguir ejerciendo tranquilamente sus prácticas. Y habiendo llegado a la conclusión de que el principal obstáculo con que tropiezan es la propia sociedad desecularizada (el «ateísmo práctico», lo llama despectivamente Massimo Cacciari), ${ }^{17}$ tanto sus portavoces ortodoxos como algunos heterodoxos se declaran solidarios de esas otras confesiones que, gracias a la inmigración, sobre todo la musulmana, aportan nuevos creyentes a Europa. ${ }^{18}$ Uno de los pensadores que, desde Quebec, se funda en tal razonamiento es Taylor:

De hecho, en muchos países occidentales hemos pasado de una primera fase, en la que el secularismo fue un logro que se obtuvo con mucho esfuerzo rechazando alguna forma de dominación religiosa, a una fase de tan gran diversidad de creencias básicas, religiosas o no, que solo un claro enfoque sobre la necesidad de equilibrar libertad de conciencia e igualdad de trato puede permitirnos formarnos un juicio de la situación. Si no, corremos el peligro de limitar innecesariamente la libertad religiosa de las minorías inmigrantes con la fuerza de nuestras soluciones institucionales históri-

${ }^{16}$ En este sentido, la figura del médico moderno sí que es una figura «secular» en comparación con el brujo ancestral. Llamo también la atención sobre el interés de Taylor en emplear la dicotomía «razón secular» y «razón religiosa», sin duda para desmentir la irracionalidad de lo religioso, y situarlo cuando menos a la par de la razón ilustrada.

17 «Ateísmo práctico» es el de la mayoría, en su irreflexiva indiferencia hacia la idea de Dios. A esas personas les trae sin cuidado que otras vivan en observancia de su fe; cf. http:// www.youtube.com/watch? $v=a C 4 H q 8 j i H i I$. Si nos atenemos a la filosofía de J. S. Mill, podrían representar una amenaza para todos ya que, al no dar opción al contraste de las posibles verdades, las abortan.

${ }^{18}$ En España, la inmigración hispanoamericana, de arraigada tradición católica. 
cas, a la vez que enviamos a esas mismas minorías el mensaje de que en modo alguno gozan de un estatus igual al de la mayoría dominante tradicional. ${ }^{19}$

A otro nivel deben interpretarse los argumentos relativos a la libertad cristiana de Benedicto XVI. «Argumentos» digo porque no aludo a «cuestiones de fe», sino al diálogo que entabló con Habermas en calidad de teólogo antes de acceder al solio pontificio. Ratzinger aseveraba que la llamada de Cristo a los hombres interpela a cada uno de ellos en su libertad más profunda. Y desde luego, en lo que se le alcanza al profano, las reiteradas palabras de Jesús, «quien quiera seguirme...» junto al detalle de los consiguientes requisitos, parecen menos una orden que arte de seducir por dificultad interpuesta. Aun así, cuán atractiva pueda resultar la llamada evangélica en nuestras sociedades secularizadas es algo que no compete dilucidar al filósofo. Más cierto se nos antoja, en cambio, que la religión institucionalizada se ha vuelto «insípida», empezando por las prácticas litúrgicas en las que la Iglesia Católica brilló a lo largo de la historia. ${ }^{20}$ ¿O no atacan al gusto de nuestros contemporáneos las tres zarandajas que endilga al féretro de turno el pobre cura desaliñado del tanatorio ${ }^{21}$ Claro que la reacción ya no es tan negativa cuando se contempla en vivo y en directo, o al menos en pantalla gigante, a un Papa carismático de punta en blanco oficiando una solemne misa cantada en un templo de lujo. Así pues, ¿estamos seguros de que no bastaría con un atrezo oportuno en el momento oportuno para que los «ateos prácticos» se rindieran a los encantos de algún que otro predicador televisivo, como sucede desde hace años en Estados Unidos? ¿Y qué más da que esto en Europa «no pase», si está pasando en la sociedad liberal-democrática que nos sirve de referente? Quizá el político europeo se enorgullezca de ello; para el filósofo, no hay motivo.

Creo que la filósofa norteamericana Martha Nussbaum es una de los que defienden la legitimidad de «religiones individuales». A lo mejor debería considerarse como tal la práctica solitaria de escuchar sermones y cantos

${ }^{19}$ Ch. Taylor, Ibid., p. 53. Taylor pretende desviar las miradas fijas en el catolicismo o cristianismo ampliando el panorama, de modo tal que no solo rodeen a aquél con igualdad dignidad otros credos religiosos, sino que la ampliación abarque cualquier ideología: «No hay razón para considerar la religión un caso especial, frente a los puntos de vista no religiosos, "seculares" (en otro sentido muy común) o ateos.» Ibid., p. 41. «El Estado no puede ser ni cristiano, ni musulmán, ni judío. Pero por la misma razón, tampoco debe ser marxista, ni kantiano, ni utilitarista.» Ibid., p. 54.

${ }^{20}$ El arte religioso merece una consideración aparte que no estoy en disposición de realizar.

${ }^{21}$ Si bien esta pregunta arrastraría otras muchas sobre la degradación actual del «culto a los muertos» (que define antropológicamente la religiosidad), solo deseo subrayar que el «gusto», en el sentido expuesto, se impone como sedimentación última de múltiples experiencias y conocimientos anteriores, no como pura impresión injustificada. El gusto sería, pues, lo espiritual del cuerpo y/o lo corporal del espíritu. 
religiosos acomodado en el sofá frente al televisor. Solo que entonces resultaría más correcto denominarla «religiosidad privada»o, ya irreverentemente, onanismo de voyeur. Pero está fuera de dudas que Nussbaum pueda decir nada lesivo para la inteligencia; por lo tanto, seguramente enfatiza la individualidad del derecho de libertad religiosa. ¿Libertad individual de credo o libertad individual de culto o los dos en uno? — vuelve la duda. ¿En qué términos cabe formular esos interrogantes, si la doctrina luterana se pervierte hasta el extremo en que la íntima comunicación entre Dios y yo se torna solipsista? Pues si mi comprensión de la divinidad no coincide con la de los demás, la mía tiene que ser la verdadera, o no podría optar a la religiosidad. ${ }^{22}$ Luego, aunque exista un único Dios para todos, solo yo tomo conciencia de Él. Restando dramatismo a la cosa, puede también expresarse en lenguaje mercantil: yo no soy el creador de Dios (ni del «prójimo», por definición comprendido en la idea de Dios); obtengo únicamente un monopolio sagrado.

Como, al parecer, se trata de que la libertad religiosa se justifica por sí sola, en la práctica daría lugar a singularísimas máximas: «que cada cual se las arregle como pueda con Él» o «que cada cual tenga el Dios que le apetezca». He ahí la otra cara del «ateísmo práctico», que hemos caracterizado por la indiferencia. Y si el ateísmo práctico — según Cacciari- difunde la estupidez, el solipsismo religioso constituye un síntoma de demencia. Tampoco los episodios de la vida de Jesús demostraban, ciertamente, un gran equilibrio mental. (Como no lo demostraron de sí mismos algunos filósofos esenciales para la razón occidental.) Pero los Evangelios crearon «norma» porque Jesús «universalizó» su doctrina aunque hiciera apartes con su $\mathrm{Pa}$ dre. ${ }^{23}$ «Dio ejemplo de vida» precisamente contra la Ley, no inscribiéndose en el censo como Profeta. Y lo que decimos de Cristo vale para cuantos profetas en el mundo han sido.

Con sus palabras acerca de la llamada que Jesucristo dirige a los hombres, Ratzinger no se limita a predicar la «libertad de religión». Por otra parte, si puede buscarse en las mismas algún nexo entre vocación y elección, no se encontrará en el alma del creyente. Es Dios quien le llama (vocare) porque Él lo elige. Ahora bien, como toda llamada pide respuesta, cuando el interpelado responde positivamente se dice que tiene «vocación religiosa»; en este sentido cabrá decir también que elige a Quien lo eligió. Sin embargo, tal elección se produce a modo de conversión. Y téngase en cuenta, además,

22 Digamos que, actualmente, una cierta epoché de la verdad propia de la religión (que es absoluta) se encuentra en la base de la tolerancia hacia otras confesiones. Si algunos autores clasifican a ésta entre las virtudes, la tolerancia para consigo mismo representaría el peor de los vicios, o más aún, una aberración.

${ }^{23}$ Primero se universalizó y después se convirtió en normal (no demencial). Lo dicho no remite, por tanto, a la ética discursiva. Tiene que ver con el hecho de que el cristianismo fue secta hasta que se convirtió en iglesia, y solo entonces logró rango institucional, esto es, jurídico. 
que Jesús no incitaba a los judíos a abandonar la sinagoga para «convertirse» a una nueva iglesia, que aún no existía. La conversión solicitada era interna; para «seguirle», el individuo debía experimentar una especie de revolución metafísica, o mejor dicho, un renacimiento espiritual. ${ }^{24}$ Puesto a elegir en semejantes circunstancias al modo en que lo concibe la filosofía anglosajona, justo entonces el discípulo llamado no elegiría — no sería libre - por carecer de alternativas (Dios es Uno) o resultarle las que tiene a mano, por demasiado heterogéneas, pésimas candidatas a una decisión racional (entre el Gran Sanedrín y el vagabundo hijo del carpintero).

Enfocando desde supuestos tales el pluralismo religioso y el creciente ateísmo, es éste el que hace más patente la imposibilidad intrínseca al acto de elegir. Cuando un ateo decide abrazar una religión, sin duda «se convierte». Si no, de no mediar la conversión en el sentido expuesto, ¿cómo iba a escoger, a santo de qué, entre cosas que no le gustan, que no le saben a nada, tan insípidas? Quizá para el individuo religioso se trate de algo más sencillo, un mero cambio de dieta. ${ }^{25}$ Eso depende, claro está, de cada cual. Pero, bien mirado, tampoco el creyente lo tiene fácil. Ni él se ahorra la conversión, sobre todo si su fe entra en crisis, pues no le bastará con elegir una nueva confesión o iglesia como quien estrena zapatos, o la que se pone el velo un domingo sí y otro no. Por una razón muy simple: religión es tradición. ${ }^{26}$

Religión es tradición; luego sentido de pertenencia, esencialismo identitario, rigidez de las costumbres que — según escribiera Aristóteles - «lo que no mandan, lo prohíben».. ${ }^{27}$ En fin, todo cuanto preocupa a quienes reflexionan actualmente sobre el tema. Así, por ejemplo, a Habermas:

Al utilizar cualquier género de razones religiosas, uno apela implícitamente a la pertenencia a la correspondiente comunidad religiosa. Solo si uno es miembro de ella y puede hablar en primera persona dentro de una tradición religiosa particular, comparte un tipo específico de experiencia de la que dependen las razones y las convicciones religiosas. ${ }^{28}$

${ }^{24}$ Me remito a un autor tan poco sospechoso como el ateo Sartre: incluso él denomina «conversión» a la elección de un nuevo «proyecto originario», porque tal elección cambia el horizonte de sentido a la vista del cual el individuo escogía antes.

${ }^{25}$ Lo he escrito en símil, pero me he dado cuenta enseguida de las dificultades reales de dicho cambio. La dieta es aún hoy un componente importante en algunas de las grandes religiones. Cf. Sarah Kofman, Calle Ordener, calle Labat, Valladolid, Cuatro.ediciones, 2003.

${ }^{26}$ ¿La predicación de Jesús era ya en su momento una religión? Lo único que nos parece claro es que era religión; pero no, o no solo, por predicar la trascendencia, decisiva para el cristianismo posterior.

${ }_{27}$ Aristóteles, Ética nicomáquea, 1138a.

${ }^{28}$ Ibid., p. 62. La cita está extraída del debate con Taylor. Como es sabido, la filosofía política de Habermas, no creyente, se apoya en una ética cosmopolita, mientras que el comunitarismo de Taylor se apoya en sus convicciones religiosas y se traduce políticamente en su defensa del independentismo quebequés. 
Ojalá que ese sentido de pertenencia se hiciera extensible a la humanidad en pleno. Desafortunadamente, ya Kant pronosticó que la «idea cosmopolita» no llegaría a realizarse. ${ }^{29}$ En otras palabras, el mundo nunca sería la Ciudad de Dios. ${ }^{30}$ Los hombres seguirían, pues, debiéndose a sus respectivos Estados, cuya unión, en el mejor de los casos, nunca implicaría obediencia a una Constitución única. En nuestras democracias, el kantismo de Habermas ha visto frustrarse incluso una Constitución Europea que ni mucho menos aspiraba al título de «contrato originario», según Kant denominó al tipo de unidad jurídica internacional (mundial) que los Estados nunca aceptarían al federarse. Y como si no hubiera bastante, el modelo habermasiano de «democracia deliberativa» tampoco prospera en una Europa cuya ciudadanía ha pasado, sin solución de continuidad, del desapego a la indignación, por efecto de una crisis que sus representantes democráticos se muestran incapaces de afrontar sin cometer injusticia. ${ }^{31}$ Así las cosas, no faltan quienes califican al «problema político-religioso» de cortina de humo que no tapa, ni aun disimula, las vergüenzas. Otros la rasgan para denunciar que los eventuales conflictos entre ilustrados laicos y fieles oscurantistas, lo mismo da si espontáneos o provocados, obedecen a la propia dinámica de la razón política europea; no solo por su vieja alianza entre el poder secular y el eclesiástico (en España, el nacionalcatolicismo de infausta memoria que encona hoy un laicismo reactivo), sino ante todo por las secuelas de un pasado colonial (en Francia, laicismo jacobino contra fundamentalismo argelino). ${ }^{32}$

Me he propuesto indagar en estas páginas los límites entre religión y política desde la filosofía. De la antropología tomo el dato de que, en los inicios de la civilización, los grupos humanos organizan la vida en común mediante pautas de conducta (prescripciones y proscripciones) religiosas. De ahí que se haya podido definir al ser humano como ser religioso. La política aparece después, nacida en medio de esas formas de relación ancestrales. Para los europeos nació en Grecia, donde Aristóteles definió al hombre como el animal político ${ }^{33}$ ¿Prescindía así de la religión? Sí y no. Prescindía de ella

${ }^{29}$ No llegaría a realizarse en el sentido de que no lo lograría plenamente. Y dado que la Idea kantiana implica totalidad, una realización parcial ya no es realización.

${ }^{30}$ Así lo formula Cacciari en su concepción de «lo impolítico».

${ }^{31}$ M. Rius, «El ciudadano sin atributos» en V. Camps et al., Democracia sin ciudadanos, Madrid, Trotta, 2010. Aunque los recientes movimientos de «indignados» parecen desmentir el leit motive de ese libro («ciudadanos sin democracia», les llama en amable autocrítica Victoria Camps), no obstante, el ejercicio de la «democracia deliberativa» en tales colectivos más bien impugna al modelo habermasiano.

32 Cf. Alain Badiou, «Derrière la Loi foulardière, la peur», Le Monde, 22.2.2004. Aunque es un artículo vociferante y paternalista, a mi juicio, tiene el mérito de especificar el cariz que toma en Francia la falsedad de quienes gobiernan.

33 Subrayo la diferencia (en perspectiva histórica) entre «ser religioso» y «animal político». La naturaleza política representa ya un grado distinto, superior o hasta superador de la animalidad. Pero la religión se distancia absolutamente de ésta; «el animal religioso» no 
en la medida en que la razón ordenadora de la pólis se construía dejando atrás la fatalidad mítica. ${ }^{34}$ Pero, en la medida en que la religión animaba las costumbres, Aristóteles la asumía con pleno convencimiento, pues ni la ley más racional debía contrariar al ethos comunitario. En política, el límite del idealismo lo señala la propia realidad humana, es decir, las costumbres de la pólis. Además, como sobre lo que (ya) es no hay elección, tampoco nadie podía elegir su (natural/tradicional) pertenencia al grupo: no era libre para ello. ${ }^{35}$

La teoría aristotélica de que la pólis no se originaba por contrato sufrió el duro golpe que le propinaron los modernos contractualistas. Sin embargo, también éstos, unos más y otros menos, en sus esfuerzos por conciliar libertad individual y seguridad estatal, tuvieron que acudir a la religión, velis nolis, como última garantía del contrato. ${ }^{36}$ Significativamente Locke, el de enfoque más razonable acerca de su viabilidad, tras establecer en defensa de la libertad individual que cada ciudadano debía poder manifestar la aquiescencia al pacto, acababa resignándose con un consentimiento «tácito». Deducimos de esto que la única prueba inequívoca de que los miembros del Estado pertenecían a él libremente se obtendría, si acaso, al decidir éstos la rescisión del contrato. ${ }^{37}$ Antes de la ruptura no había forma de saber si asentían por propia voluntad o practicaban, al contrario, alguna forma de sumisión; a menos, claro está, que esporádicas revueltas indicasen lo segundo.

Intentaré ahora atar los cabos sueltos después del excurso por el pasado de la filosofía política. Como se ha visto, hay amplio consenso entre discursos de todo signo en la justificación de las creencias religiosas a partir de la libertad individual de conciencia - que es producto del cristianismo, lo recalco sin vanagloria. Ahora bien, dada la secularización del concepto, no todos los autores lo entienden de la misma forma, y a menudo le asignan funciones diversas. Algunos (Habermas, Taylor) destacan los vínculos entre religión y tradición, si bien con el predominio, o incluso la trascendencia, de una de las dos. ${ }^{38}$ En cambio, los autores anglosajones tienden a interpretar la libertad como capacidad de elección según el modelo del contrato. No se trata de una oposición neta, pues Habermas coincide con ellos, eminente-

existe. Se da, pues, entre religión y política un abismo insalvable. Por esto algunos coronarán al hombre con el epíteto de «abismático».

${ }^{34}$ Sobre la absorción, luego asunción, de los ritos ancestrales por la razón política a través del derecho, según lo fabularon las tragedias griegas (Orestes, Antígona, etc.), han escrito abundantemente los filósofos contemporáneos.

${ }^{35}$ Lógicamente, porque el individuo solo es libre como ciudadano, dentro de la pólis ya constituida.

${ }^{36}$ Desde Hobbes, con las «leyes naturales» de potencial socializador, hasta Rousseau, con la «religión civil».

${ }^{37}$ Por esto afirma Hobbes que no pueden rescindirlo, porque para ello hay que mantenerse libre.

${ }^{38}$ Por supuesto, la trascendencia solo corresponde a la religión. 
mente con Rawls, al dictaminar que las «normas de justicia» deben prevalecer sobre las «concepciones del bien», esto es, las leyes del Estado sobre las creencias religiosas. ${ }^{39}$ Con todo, la pertenencia a una tradición no se elige, y por tanto, a una religión tampoco (o solo mediante previa «conversión»).

Dicho impedimento obliga al teórico a matizar la noción de libertad que profesan las tradiciones religiosas. En este sentido, desde el prólogo a una reciente edición francesa del opúsculo de Benedetto Croce «Perché non possiamo non dirci “cristiani"» (Por qué no podemos no decirnos «cristianos»), Jean-Luc Nancy compara su título con el de Russell, «Por qué no soy cristiano». A su juicio, ese «decirnos» de Croce significó en su día una aminoración del «soy» russelliano. Tal vez sí... aunque a mí no me lo parece; esperaré la ocasión de argumentarlo. ${ }^{40}$ Por el momento sostengo que mi tradición, mi cultura, mi religión, mi lengua me constituyen en lo que «soy» -realmente. Y en éstas empieza mi libertad; para rendirles culto, despreciarlas, o sustituirlas en futuras conversiones. Asimismo, desde luego, para abrirme a la comprensión de lo que «son» los otros, y compartir con ellos algo o mucho más de lo que «somos».

Con tales premisas resulta absurda la idea de que, si una chica musulmana ha «decidido libremente» ponerse el velo, nada debe objetársele, ni siquiera para intentar persuadirla de que se lo quite. Entiéndase: lo absurdo de la idea no invalida el consejo pragmático, o incluso ético, que se brinda al posible entrometido. ${ }^{41}$ Sin embargo, por todo lo que llevamos dicho se comprenderá que la presunta decisión de velarse no es menos ficticia que el libresco contrato originario. Y no por casualidad. En general, con buen tino, los autores que aducen la libertad como argumento evitan las oscuridades metafísicas; se detienen, por tanto, en la libre elección contractual. Pero ahí está el error, pues — según el clásico — no hay modo de verificar la conformidad (tácita) hasta que el sujeto la retira. Esta paradoja cae ya en el absurdo así que se la utiliza inopinadamente para dar razón. No cabe negar de la chica musulmana del ejemplo que sea libre durante todo el período de su vida en que no se quita el velo. Solo que, para sus semejantes, ello se queda en mera hipótesis. Por lo demás, el acto de descubrirse quizá tampoco acredita finalmente su indemostrable libertad en el pasado; a lo mejor la libertad, instantánea, se cifra en el puro «liberarse» - como se ha dicho tantas veces. En conclusión, la libertad no sirve de argumento. Puede que no sirva en

${ }^{39}$ Es de sobra conocido que el mencionado acuerdo básico no impidió el desacuerdo entre ambos autores acerca del grado de visibilidad de la religión en el espacio público.

${ }^{40} \mathrm{M}$. Rius, «El regust de les cometes», Via, 18, Barcelona, Centre de Estudis Jordi Pujol, 2012, pp. 143-149.

${ }_{41}$ Taylor respecto a la ley francesa de prohibición del hiyab en las escuelas públicas: «Quizá lo más pernicioso de este fetichismo es que tiende a ocultar los auténticos dilemas con que nos encontramos en este campo, y que saltan a la vista en cuanto reconocemos la pluralidad de los principios en juego.» Ibid., p. 46. De dicha pluralidad de principios son reflejo los 32 puntos que Badiou considera en el artículo antes citado sobre el foulard. 
ninguna de las tentativas de justificar así un acto: «lo hago porque soy libre, nadie me obliga». ${ }^{42}$ Cuántas acciones habrá de ese calibre que infringen las normas de justicia. Y aún muchísimas más que, al no perjudicar en nada a nadie, no deberían cuestionarse, aunque solo fuera por no malgastar el tiempo. Afortunadamente, el sentido común de la mayoría se desentiende de tamaños interrogatorios. A excepción de los filósofos, en especial los de tradición analítica.

Enemigo de la casuística como buen kantiano, Habermas ha revalidado en los últimos años su vieja pertenencia a la Escuela de Frankfurt. Primero recuperó el concepto-límite de «naturaleza» humana para someter a crítica el nuevo «transcendental» de la biotecnología. Más tarde se preguntó por los límites del discurso religioso en el espacio público. En ambas ocasiones, un detonante fáctico. En la segunda fue el nuevo pluralismo religioso de las sociedades democráticas occidentales. Va de soi la relevancia de este fenómeno para los pensadores que, como él, reflexionan sobre la moralidad de la política. No obstante, para Habermas reviste un doble interés, ya que la cohabitación en el espacio público europeo de lenguajes tan diferentes somete a prueba de fuego su teoría de la acción comunicativa, que siempre despertó objeciones a la eficacia del diálogo según lo concebía. Pues bien, Habermas se ratifica en su procedimentalismo al defender ahora, como posible enriquecimiento social, la interacción de subjetividades formadas en un contexto religioso con otras que se mantienen fuera de éste. Incluso espera que la ganancia se objetive, más allá de los sujetos particulares, en nuevas construcciones de sentido que inocularían vitalidad a una razón sumida en horas bajas. Otro efecto deseable podría ser la «motivación» de que los ciudadanos de nuestras democracias van escasos. ${ }^{43}$ De todos modos, aunque esto último preocupe a Habermas, su cognitivismo se eleva por encima de la creencia. ${ }^{44}$

Pese a su franca moderación, comparada con el disgusto de los fundadores de la Teoría Crítica hacia la «razón maltrecha», Habermas no deja de acercarse a las posiciones de Adorno (quien, a su vez, debe mucho a Benjamin) en lo concerniente a las potencialidades del lenguaje religioso desde el punto de vista cognoscitivo. Adorno las sospesaba en relación inversamente proporcional a la creencia: «La posibilidad a que se refiere el nombre divino

${ }^{42}$ Se trata, al cabo, del lo-hice-porque-quise que Wittgenstein comenta en su Conferencia sobre ética. El sujeto de una acción no la fundamenta por el mero hecho de representarse - kantianamente - como libre. Lo que importa es el contenido de la misma. El resto, puro formalismo inmoral. (Al que Kant es completamente ajeno, por supuesto.)

${ }^{43}$ De esta escasa motivación nos habla el último libro de Camps, El gobierno de las emociones (Barcelona, Herder, 2011), en el que la autora aprecia el valor de la ficción artística, pero sin ocuparse de la religión.

${ }_{44} \mathrm{Si}$ acaso, seguiría a Spinoza en su defensa de la libertad del sabio (por «adhesión»a la verdad como index sui), y no en su «tolerancia» hacia las supersticiones populares en bien del orden político. 
la retiene el que no cree». ${ }^{45}$ Con estas palabras alertaba sobre la necesidad de alguna forma de trascendencia; pero entendida como un trascender la fe racional en el progreso histórico, no como fe en lo sobrenatural no empírico. En suma, el armazón teológico de la filosofía hegeliana —el Espíritu (Geist) como versión secular del misterio de la Santísima Trinidad- cedía al mesianismo de tradición judía, en el que se inició Benjamin. ${ }^{46}$ No fue flor de un día. Aún hoy, al predicamento de que goza la obra de Benjamin se añade el del deconstruccionismo, que también Derrida orientó progresivamente por aquella senda. Así pues, en España, el furibundo laicismo de bastantes intelectuales no rechaza en absoluto, sino todo lo contrario, una teología política de nueva factura. Bromeando un poco, diríase que el judaísmo no les parece entrañar los peligros de la religión porque «la verdadera» es la católica.

Habermas se limita a constatar la posibilidad del diálogo sin entrar en disquisiciones sobre qué pueden aportar de lo que nos falta las distintas religiones. Espera de ellas que generen perspectivas inéditas dentro del espacio público, en vez de tenernos absortos en lo que nos ha conducido donde estamos. Se trata de mirar hacia delante. Con todo, resulta innegable que el autor deposita sus esperanzas en el influjo de un pasado común; en la historia, al fin y al cabo, puesto que la interfecundación de las tres grandes religiones marcó los comienzos de Europa. Baste con recordar la interpretación judía y árabe de Aristóteles. En efecto. ¿Pero se esconde ahí el secreto de la buena convivencia para nuestras sociedades laicas, cristianas en el pasado y hoy con un significativo número de inmigrantes de religión musulmana? Además, como le recuerda Taylor, han desembarcado en Europa otras religiones no monoteístas:

Quiero decirte una cosa más. Cuando hablamos de «religión», no debemos pensar solo en el cristianismo. Hay budistas, hay hindúes. Muchas de las cosas que dices en absoluto pueden aplicarse a otros casos. Esto debería darnos que pensar antes de generalizar. ${ }^{47}$

Conjeturamos que para eso están las «normas de justicia», para contener éticamente, en pro de la convivencia, las distintas «concepciones del bien». Pero tal solución nos devuelve al punto de partida. Se buscaba en las religiones una salida del marasmo social y, al primer contratiempo, se las pone en su sitio, bajo estricta tutela del orden político. Bien está; solo que la nutricia apertura a los contenidos religiosos no nos ha librado del ascetismo procedimental. Más bien ha quedado reducida a simple contingencia, es

${ }^{45}$ Th. W. Adorno, Dialéctica negativa, O.C., Madrid, Akal, 2005, p. 367.

${ }^{46}$ Como se sabe, Benjamin intentaba conjugar mesianismo y marxismo. Quizá algunos dirán que no hacía falta, y no porque Marx tuviera ascendencia judía, sino porque la idea de revolución ya es en sí (ruptura) mesiánica. Se trata, desde luego, de una interpretación extremadamente superficial y, en consecuencia, incorrecta.

${ }^{47}$ Ibid., p. 68. 
decir, a una oportunidad para que la religión, siendo necesaria, se niegue, por tanto, a sí misma. ${ }^{48}$ Curiosamente, algunos de sus abanderados, si no feligreses, se adelantan en la autoaplicación de los principios de sus oponentes laicos. En este sentido actúa la propuesta más liberal de todas, que consiste en una «religión de heterodoxos» (la denominación es mía). Se trata de que cada cual pueda disfrutar de unas creencias religiosas compartidas, pero siempre desde su individual apropiación de las mismas. ${ }^{49}$ No obstante, como suponemos que este tributo a la libertad de conciencia se realiza con el fin de maximizar los beneficios de la unión, no debe de estarle permitido sabotear lo que para algunos será una "comunidad de espíritu», y para otros un «club de salvación». De hecho, la nueva fórmula descrita pone coto a lo que más atrás he llamado «monopolio de lo sagrado». En fin, no se ve otra solución a los conflictos, si persisten, que la de reproducir el esquema entre bien y justicia: unas normas generales deberán proteger al grupo de creyentes de sus excesos individualistas. A la postre, el modelo religioso y el laico se reflejan entre sí especularmente. Luego, el uno frente al otro, ciegos para lo que no quede atrapado en sus reflejos mutuos, se encapsulan. Dicha situación tiene un nombre clásico: inmanencia. Contradice lo esencial de nuestras religiones, que es el afán de trascendencia. ${ }^{50}$

Escribía en los años setenta Henry Corbin, islamista de prestigio, que la única conciliación posible entre los tres grandes monoteísmos residía en la mística. ${ }^{51}$ Con este aserto no preconizaba éxtasis o transportes; ni ironizaba, en actitud opuesta, acerca de las virtudes del silencio. Pero, visto ahora, tampoco ayudaba demasiado a confiar en una secularización al unísono, a través de la confluencia surgida en y del trato político. Sin embargo, Habermas quiere extraer del diálogo interreligioso un rendimiento sociopolítico; no demuestra otro objetivo al apoyarlo. No aspira a ningún tipo de trascendencia, ni ultramundana ni mundana, ni eterna ni histórica. ${ }^{52}$ Por lo demás, resulta casi impertinente cotejar su filosofía de la acción comunicativa con el místico desbordamiento de los límites del lenguaje. Pero está justificado

${ }^{48}$ Se entiende «necesidad» por oposición a «contingencia»; luego en sentido contrario al de la nota que sigue a ésta.

${ }^{49} \mathrm{La}$ fórmula empleada habitualmente es «de acuerdo con sus necesidades». He ahí a la religión devenida en medio de autoconservación. Se rebate así mi afirmación anterior de que no existe «el animal religioso». Por otro lado, el propio Aristóteles, al definir al hombre como «el animal político», precisó que el fin de la ciudad no se reducía a la satisfacción de las necesidades.

${ }^{50}$ Como es obvio, este artículo debe entenderse en el marco del cristianismo, por razones no menos obvias.

${ }^{51}$ H. Corbin, El hombre y su ángel, Barcelona, Destino, 1995.

${ }^{52}$ Se aparta en ello de su inmediato predecesor en la teoría crítica, Adorno. Y se sitúa directamente en contra de las aspiraciones de su actual interlocutor, Charles Taylor, cuyo comunitarismo nada tiene que ver con la negatividad utópica adorniana. A distinguir ambas opciones apunta mi referencia a lo mundano o histórico y lo ultramundano o eterno. 
para despejar alguna incógnita. Cacciari, que también invoca el pasado común de los tres monoteísmos, considera la mística como la única experiencia religiosa absolutamente irreconciliable con la política:

A la sistemática afinidad entre teología y derecho se opone, sin embargo, la que hay entre mística y justicia. Y creo que el sentido de la Gerechtigkeit no debe buscarse tanto en la benjaminiana imagen bíblica de la «pura violencia divina», fulmínea y no sangrienta, «que es santo y seña», como en la idea de una lengua sustraída a lo discursivo, a lo teológico precisamente, y renovándose constantemente en las fuertes de la Palabra justa. ${ }^{53}$

Por lógica, puesto que la suya es una ética del discurso, Habermas se fía más de la teología. Obviamente, no para recaer en la «teología política». ${ }^{54}$ Política y religión deben mantenerse a distancia. Aquí no afecta al argumento la ineludible distinción conceptual entre religión y teología - la primera, más ligada a la creencia, la segunda al conocimiento-, pues no se nos alcanza cómo podría haber teología sin religión (pese al tópico de que nadie con menos fe que los teólogos). ${ }^{55}$ Escrupulosamente, ni Habermas ni Cacciari mezclan lo político con lo religioso; pero ambos creen en el papel mediador de la filosofía. Y también se aferran los dos al monoteísmo de la «única razón» que se despliega pluralmente: «a nivel cognitivo general, solo existe una y la misma razón humana» - subraya Habermas. ${ }^{56}$ Es la vieja búsqueda de la unidad en la multiplicidad, solo que experimentada ahora como racionalidad universal en un mundo paradójico. ${ }^{57}$ Nietzsche ventiló a su modo el insoluble problema de Platón con lo Uno y lo Múltiple. Nada nos resta por añadir sin desbaratar este artículo.

¿Hasta cuándo la religión? Sine die en caso de que ser humano signifique ser religioso. Mientras nuestro planeta sobreviva, alguien habrá para preguntarse dónde está «la sal de la tierra». Quizá nuestros descendientes ya no se reconforten entre sí diciendo "vaya usted con Dios». Quizá prefieran algo más jovial o más prosaico, como «que la suerte te acompañe». Pero, a decir verdad, ¿no es la Fortuna una diosa?

${ }^{53}$ M. Cacciari, «Derecho y justicia. Ensayo sobre las dimensiones teológicas y místicas de la política moderna», Anales de la Cátedra Francisco Suárez, n. ${ }^{\circ}$ 30/1990, Universidad de Granada, p. 66. También en M. Cacciari, The Unpolitical. On the Radical Critique of Political Reason, New York, Fordham University Press, 2009, p. 183.

${ }^{54} \mathrm{Su}$ participación en el citado volumen colectivo es precisamente un rechazo de la filosofía política de Schmitt: «Lo político: el sentido racional de una cuestionable herencia de la teología política».

${ }^{55}$ Existen, naturalmente, religiones sin teología. De ahí que la diferencia entre ambas merezca una reflexión aparte.

56 Ibid., p. 62.

${ }^{57}$ Por ello Cacciari, amante a la vez del lógos y de la paradoja, se acoge a la mística de Wittgenstein como filósofo. En el diálogo con la teología que gusta de practicar, no descuida que ambos extremos se dan unidos en la figura de Jesucristo. 


\section{BIBLIOGRAFÍA}

Adorno, Th.W. (2005): Dialéctica negativa, Madrid, Akal.

Aristóteles (1985): Ética nicomáquea, Madrid, Gredos.

Cacciari, M. (2009): The Unpolitical. On the Radical Critique of Political Reason, New York, Fordham University Press.

Camps, V., ed. (2010): Democracia sin ciudadanos, Madrid, Trotta.

Camps, V. (2011): El gobierno de las emociones, Barcelona, Herder.

Corbin, H. (1995): El hombre y su ángel, Barcelona, Destino.

Habermas, J., Taylor, Ch., Butler, J., West, C. (2011): El poder de la religión en la esfera pública, Madrid, Trotta.

Kelsen, H. (1988): Dio e Stato. La giurisprudenza come scienza dello spirito, Napoli/Roma, Edizioni Scientifiche Italiane.

Kofman, S. (2003): Calle Ordener, calle Labat, Valladolid, Cuatro ediciones.

Rius, M. (2012): «El regust de les cometes», Via n. ${ }^{\circ}$ 18, Barcelona, Fundació Jordi Pujol.

Russell, B. (2009): Por qué no soy cristiano, Barcelona, Edhasa. 